\title{
INFLUENCE OF A PHYSICAL TRAINING PROGRAM ON MUSCLE STRENGTH, BALANCE AND GAIT VELOCITY AMONG WOMEN WITH OSTEOPOROSIS
}

\author{
Aveiro MC ${ }^{1}$, Granito RN ${ }^{1}$, Navega MT ${ }^{1,2}$, Driusso $\mathrm{P}^{1}$ e Oishi $\mathrm{J}^{3}$ \\ ${ }^{1}$ Departamento de Fisioterapia, Centro de Ciências Biológicas e da Saúde, Universidade Federal de São Carlos - \\ UFSCar, São Carlos, SP - Brasil \\ ${ }^{2}$ Departamento de Educação Especial, Faculdade de Filosofia e Ciências, Universidade Estadual Paulista Júlio de \\ Mesquita Filho, Campus de Marília, Marília, SP - Brasil \\ ${ }^{3}$ Departamento de Estatística, Centro de Ciências Exatas e Tecnologia, UFSCar, São Carlos, SP - Brasil \\ Correspondencia para: Mariana Chaves Aveiro, Rua Espir Nicolau Bichuetti, 134, Bairro São Benedito, CEP 38020-590, \\ Uberaba, MG - Brasil, e-mail: mariaveiro@yahoo.com
}

Recebido: 30/01/2006 - Revisado: 01/06/2006 - Aceito: 21/09/2006

\begin{abstract}
Objectives: The trend towards increased life expectancy will certainly lead to increases in morbidity and mortality relating to osteoporosis. Because of the lack of well defined protocols on the intensity and frequency of easily performed physical exercises for Brazilian women, this study proposed to analyze the effects of a training program for ankle muscle strength, balance performance and gait velocity among women with a densitometric diagnosis of osteoporosis. Methods: Twelve female volunteers (age $68.7 \pm 2.7$ years) underwent physical evaluation and subsequent reevaluation after twelve weeks. The physical activity program was guided by a physical therapist, who conducted 60-minute sessions, three times a week for twelve weeks. Each training session included some stretching exercises, strengthening exercises for the ankle dorsiflexor and plantar-flexor muscles, with $50 \%$ of 10 -repetition maximum (10-RM), and balance training. Results: The variables analyzed regarding balance index, gait velocity and muscle strength presented significant improvement $(\mathrm{p} \leq 0.05)$, as shown by the Wilcoxon non-parametric test. Conclusion: After the 12-week exercise program, the participants presented benefits in terms of their fitness. The results demonstrate that the training had a role in improving the condition of this group of patients, thus suggesting that this program was effective, easy to implement and safe for Brazilian women with osteoporosis. Therefore, it can be seen that physical activity programs are efficient in improving balance performance, gait velocity and ankle muscle strength among elderly women with osteoporosis.
\end{abstract}

Key words: balance, physical training, gait velocity, muscle strength, osteoporosis.

\section{RESUMO}

\section{Influência de um Programa de Treinamento Físico na Força Muscular, no Equilíbrio e na Velocidade da Marcha de Mulheres Portadoras de Osteoporose}

Objetivos: A tendência de aumento na expectativa de vida certamente representará incrementos na morbidade e na mortalidade em eventos relacionados a osteoporose. Devido à falta de protocolos bem definidos na intensidade e freqüência de exercícios físicos, que sejam fáceis de se realizarem, para mulheres brasileiras, este estudo propôs analisar os efeitos de um programa de treinamento na força muscular do tornozelo, no equilíbrio funcional e na velocidade da marcha de mulheres com diagnóstico densitométrico de osteoporose. Métodos: Doze mulheres voluntárias (idade 68,7 \pm 2,7) foram submetidas à avaliação física e, posteriormente, reavaliadas após doze semanas. O programa de atividade física foi orientado por um fisioterapeuta, que trabalhou 60 minutos, 3 vezes por semana, por doze semanas. Cada sessão de treinamento incluiu alguns exercícios de alongamento, fortalecimento muscular dos músculos flexores plantares e dorsiflexores do tornozelo, com 50\% de 10-repetições máximas (10$\mathrm{RM}$ ) e treino de equilíbrio. Resultados: As variáveis relacionadas ao índice de equilíbrio, à velocidade da marcha e à força muscular apresentaram melhora significativa $(\mathrm{p} \leq 0,05)$, analisadas por meio do teste não paramétrico de Wilcoxon. Conclusão: Após as doze semanas de treinamento, foram observados benefícios no condicionamento das voluntárias. Os resultados demonstram que o treinamento proposto, teve influência na melhora desse grupo de pacientes, sugerindo que o programa foi efetivo, fácil 
e seguro para mulheres brasileiras portadoras de osteoporose. Portanto, programas de atividade física são eficientes para melhorar o equilíbrio funcional, a velocidade da marcha e a força muscular do tornozelo de mulheres idosas portadoras de osteoporose.

Palavras-chave: equilíbrio, treinamento físico, velocidade da marcha, força muscular, osteoporose.

\section{INTRODUCTION}

The trend towards increased life expectancy will certainly lead to increased morbidity and mortality relating to osteoporosis ${ }^{1}$. With advancing age, an increasing number of American women develop osteoporosis. Estimates from Europe suggest that about $23 \%$ of women aged 50 years old or over have osteoporosis ${ }^{2}$. In Brazil, data are scarce and the precise economic and social impact of osteoporosis has yet to be defined.

At least 1.3 million fractures are attributed to osteoporosis in the USA each year ${ }^{2}$. The three sites most frequently associated with osteoporosis are the hip, spine and distal forearm ${ }^{2,3}$. Hip fracture is often the result of falling down from a standing position, although it may also occur spontaneously. It is usually painful and quite often requires hospitalization $^{3}$. The quality of life for survivors may be severely impaired. One year after a hip fracture, $40 \%$ of such patients are unable to walk independently and 60\% are unable to carry out at least one activity of daily living².

The high medical costs associated with hip fracture can have a devastating effect on the already underfunded healthcare systems in underdeveloped countries. Reducing the incidence of hip fracture by preventing osteoporosis will lessen the impact of this catastrophic increase in fractures ${ }^{4}$.

Several factors are significantly associated with the risk of subsequent hip fracture: BMD (bone mineral density), calcium consumption, physical activity (daily outdoor walking), functional capacity (inability to perform activities of daily living, motion difficulty score and use of a cane), neuromuscular performance (gait velocity, chair stand performance and balance performance), visual acuity, leg weakness, history of stroke, use of sedatives, history of falls over the past six months and fear of falling ${ }^{5,6}$.

Many elderly people experience difficulty in performing activities of daily living, because the strength-generating capacity of their skeletal muscles is reduced ${ }^{7}$. Muscle strength declines by approximately $15 \%$ per decade in the sixth and seventh decade and $30 \%$ per decade thereafter ${ }^{8}$. The weaker muscles of an elderly person may compound the problem of brittle bones by increasing the risk of a fall and therefore the possibility of sustaining a fracture ${ }^{9}$.

The results from the study by Daubney and Culham ${ }^{10}$ support findings from previous studies suggesting that the strength-generating capacity of the distal musculature is important for maintaining older adults' balance.

Thus, exercise is important in maintaining functional independence among the elderly because it improves muscle strength, coordination and balance performance and decreases the risk of falls and fractures ${ }^{11,12}$.

Progressive resistance training and progressive functional training are safe and effective methods for increasing strength and functional performance and for reducing falls related to behavioral and emotional restrictions during outpatient rehabilitation among frail high-risk geriatric patients with a history of injurious falls ${ }^{13}$.

High-intensity resistance training not only has a protective effect on the femoral neck BMD and lumbar spine BMD but also increases muscle mass, strength, dynamic balance and overall physical activity levels among postmenopausal women. All of these outcomes may mediate a risk reduction for future osteoporotic fractures, by simultaneously influencing multiple risk factors ${ }^{14}$.

Because of the lack of well-defined protocols regarding the intensity and frequency of easily performed physical exercises for reducing the multiple risk factors for falls among Brazilian women, the present study proposed to analyze the effects of an exercise training program on ankle muscle strength, balance performance and gait velocity among women with a densitometric diagnosis of osteoporosis.

\section{METHODS}

The Research Ethics Committee of the Federal University of São Carlos gave its approval for this study (Protocol Number 029/2004). The women who took part in the exercise program were informed about the study characteristics, in accordance with Resolution 196/96 from the National Health Council. These volunteers provided their written informed consent in order to participate in this study.

Sixteen volunteers with a densitometric diagnosis of osteoporosis in the lumbar spine or femoral neck were evaluated, but only twelve finished the study. Women with neurological or orthopedic disorders or those who did not attend $75 \%$ of the sessions were excluded from the study. No control group was included in this study because it was considered unethical to exclude some participants from the exercise program, since the benefits of physical exercise to human health are well established.

The twelve women $(68.7 \pm 2.7$ years old $)$ included in this study underwent physical evaluation, balance testing and gait velocity and isometric peak torque evaluation. After the twelve-week training program, the volunteers were reevaluated. 


\section{Physical evaluation}

Personal data and information on pain, previous fractures, other disorders and medical treatment were collected. Weight, height, blood pressure and heart rate were registered.

\section{Balance test}

A protocol developed by Caromano ${ }^{15}$ consisting of static and dynamic balance tests was followed. The static balance test included a thirty-second single leg stance with the arms hanging straight down alongside the hips and a thirty-second single leg stance with the arms abducted to 90 degrees followed by a thirty-second single leg stance with the arms horizontal to the leg stance, while carrying out circular movements. Each posture was carried out with both the right leg and the left leg, thus totaling six static balance tests. Two static and three dynamic balance tests were performed in a sequence, requiring each volunteer to stand on their tiptoes for 30 seconds, stand on their heels for 30 seconds, step over a distance of 0.5 meters, sit down on a chair and then stand up. The 11 tests performed were graded from 1 to 5 , according to established criteria. Through this assessment it was possible to create a balance performance index (BpI). This index ranged from 11 (best balance) to 55 (worst balance).

\section{Isometric Peak Torque Evaluation}

The isometric peak torque for the plantar flexors and dorsiflexors was assessed using a BIODEX 2 isokinetic dynamometer. The test was performed with the volunteer seated, belts placed over her thorax and abdomen, knees at 30 degrees and ankles at neutral (0 degrees). The foot was attached to a footplate and held in a fixed position by a belt. The ankle joint was aligned with the dynamometer axis, as recommended in the Biodex manual. Isometric evaluations were chosen in order to minimize errors during data collection because these elderly and sedentary volunteers were likely to have difficulty performing isotonic ankle muscle contractions. The ankle muscles were strengthened over all ranges of ankle motion that were tested, including the neutral position.

Before being tested, all the volunteers performed three submaximal repetitions as a warm-up exercise in order to become familiarized with the equipment. They were instructed to push down (plantar flexors) and pull up (dorsiflexors) on an immovable plate. They performed three valid maximal voluntary contractions for each movement, as forcefully as possible for a time of five seconds. A three-minute interval between the repetitions was maintained in order to minimize fatigue. The tests were performed bilaterally, always beginning on the right side. The participants were told not to hold onto the lateral supports during the test. Blood pressure and heart rate were measured in order to maintain safety during the assessment. The isometric strength was determined as the highest peak torque (Nm) among the three trials analyzed.

\section{Gait Velocity Evaluation}

The usual and maximum gait velocities were measured using a digital chronometer. The volunteers walked eight meters, with the pace timed from two to eight meters in order to exclude speed variation during acceleration. The gait velocity was calculated by dividing six meters by the time recorded ${ }^{12}$.

For this assessment, each volunteer was asked to walk at a self-selected velocity (usual velocity). For this usual pace, the volunteer was instructed to walk as she normally did. After a two-minute break, she was asked to walk as fast as she could without running, to determine maximum gait velocity ${ }^{12}$.

\section{Exercise Training Program}

After the baseline assessments, the volunteers started an exercise program on three days per week for 12 weeks, under the supervision of a physical therapist. The volunteers were divided into two groups according to their own schedule preferences.

Each training session consisted of stretching exercises, a walking exercise, ankle muscle strengthening and balance training. Heart rates were measured at the beginning of the session and at 20-minute intervals, in order to monitor the level of activity and to prevent participants from walking at more than $75 \%$ of heart rate for their age.

Static stretching exercises were carried out for the muscles of the neck, back, arms and legs at the beginning of the session and were followed by the walking exercise. The volunteers were instructed to walk along a track at a selfselected velocity for twenty minutes as a warm-up exercise before muscle strengthening.

The participants performed ankle plantar flexion by lifting the heels while standing on their feet. Initially, during the adaptation period, the individuals performed four sets of ten bilateral plantar flexion lifts. After four weeks, the participants progressed to unilateral plantar flexion, two sets of ten lifts for each leg. In order to increase the workload, the toes and balls of the feet were placed on a five-centimeter support, beginning at the first session. Each repetition lasted 6 seconds and the physical therapist conducting the session gave a oneminute rest period between sets to minimize fatigue.

Ankle dorsiflexion was performed with $0.5,1$ or $2 \mathrm{~kg}$ cuff weights that were wrapped around the front parts of the participants' feet. In order to determine the weight that each volunteer could lift, a ten-repetition maximum test (10RM) was carried out. This test evaluates the maximum load that a person can lift in 10 complete movements with little action by the muscle groups that are not the muscles primarily responsible for the movement evaluated. In order to determine the 10-RM, incremental loads were added until failure occurred. The heaviest load that was successfully lifted 10 times was designated the 10-RM for ankle dorsiflexion. The 10-RM was determined over two to three attempts, with a three-minute interval between them. 
The 10-RM was carried out at baseline and after four and eight weeks. The volunteers performed two sets of 10 lifts with $50 \%$ of the last 10-RM. The participants strengthened their ankle dorsiflexors by means of 30 degrees of hip flexion while standing erect. The dorsiflexion was carried out for the full range of ankle motion with cuff weights around the front part of the participants' feet. Each repetition lasted six seconds and a one-minute rest to minimize fatigue was given between sets.

Balance training was performed in the static and dynamic positions. The participants carried out backward and tandem walking for 10 meters, and walked 10 meters on their heels and tiptoes. Following this, they were asked to stand on one leg, on their heels and on their tiptoes and perform tandem standing, for 40 seconds.

During balance training, the volunteers were allowed to hold onto the rail while recovering their balance. If it was seen that one of the volunteers was finding it easy to do the exercise, this person was asked to close her eyes during the static balance training.

Table 1. Characteristics of the Subjects that were included in the training.
At the end of each session, some static stretching exercises were performed in order to stabilize the heart rate and promote relaxation.

\section{Statistical Analysis}

The statistical analysis was performed using nonparametric tests. The comparison between the baseline and outcome measurements was made using the Wilcoxon Test. The level of significance used for all comparisons was $5 \%$ ( $p \leq 0.05)$. The data were expressed as means \pm standard deviations.

\section{RESULTS}

Table 1 shows the characteristics of the 12 individuals who completed this trial.

Table 2 shows the effects of the exercise training program on ankle muscle strength, balance performance and gait velocity, for all baseline and outcome mean measurements.

\begin{tabular}{lc}
\hline \multicolumn{1}{c}{ Characteristic } & Exercise Group $(\mathrm{n}=12)$ \\
\hline Age (years) & $68.7 \pm 2.7$ \\
Years since menopause (years) & $23.25 \pm 5.03$ \\
Height $(\mathrm{m})$ & $1.5 \pm 0.1$ \\
Weight $(\mathrm{kg})$ & $57.4 \pm 11.1$ \\
Body mass index $\left(\mathrm{kg} / \mathrm{m}^{2}\right)$ & $25.0 \pm 6.1$ \\
Lumbar bone mineral density $\left(\mathrm{g} / \mathrm{cm}^{2}\right)$ & $0.822 \pm 0.109$ \\
T-score & $-3.16 \pm 0.90$ \\
Femoral neck bone mineral density $\left(\mathrm{g} / \mathrm{cm}^{2}\right)$ & $0.685 \pm 0.076$ \\
T-score & $-2.51 \pm 0.57$ \\
\hline
\end{tabular}

Data are expressed as mean \pm standard deviation.

Table 2. Effects of the Exercise Training Program, after 12 weeks.

\begin{tabular}{lccc}
\hline & Baseline & $\begin{array}{c}\text { After 12 weeks } \\
\text { of training }\end{array}$ & p-value \\
\hline Right plantar flexor peak torque (Nm) & $50.83 \pm 15.78$ & $61.14 \pm 18.20$ & $0.0037 *$ \\
Left plantar flexor peak torque (Nm) & $51.80 \pm 15.29$ & $59.58 \pm 15.43$ & $0.0029 *$ \\
Right dorsiflexor peak torque (Nm) & $16.58 \pm 4.16$ & $20.49 \pm 4.25$ & $0.0022 *$ \\
Left dorsiflexor peak torque (Nm) & $16.85 \pm 3.91$ & $20.81 \pm 3.92$ & $0.0022 *$ \\
Balance performance index & $23.17 \pm 6.25$ & $19.92 \pm 8.52$ & $0.0178 *$ \\
Usual gait velocity (m/s) & $1.25 \pm 0.16$ & $1.31 \pm 0.13$ & $0.0108 *$ \\
Maximal gait velocity (m/s) & $1.75 \pm 0.27$ & $1.83 \pm 0.30$ & $0.0218 *$ \\
& & & \\
\hline $\begin{array}{l}\text { Data are expressed as mean } \pm \text { standard deviation; p-value based on Wilcoxon test; } \\
\text { * Significant (p } \leq 0.05) .\end{array}$ & & &
\end{tabular}


Every variable analyzed improved significantly after 12 weeks of the exercise training program. The means for the right and left plantar flexor torque increased by $20 \%$ and $15 \%$, respectively. The means for the right and left dorsiflexor torque increased by $24 \%$. The mean balance performance index decreased by $16 \%$, which was a significant improvement in balance performance. The means for the usual and maximum gait velocities increased by $4.8 \%$ and $4.6 \%$, respectively.

\section{DISCUSSION}

The rate of decline in strength and muscle mass over the course of old age and the accompanying loss of independent functional capacity can be reduced or even reversed by appropriate resistance training programs ${ }^{16}$. Traininginduced adaptations in skeletal muscles depend on the intensity, frequency, duration and type of exercise ${ }^{7}$.

There was a significant increase in isometric peak torque for plantar flexors and dorsiflexors in this study. Therefore, the proposed exercise training program was efficient in strengthening the ankle muscles of these elderly women with osteoporosis. As the volunteers were sedentary, an adaptation period and low workload during training were necessary. These factors also affected the muscle strength evaluation. In order to minimize fatigue, characterized by a decrease in peak torque accompanied by pain or spasm, an interval was permitted between repetitions. By three to four minutes after acute exercise, the muscles recover to $90-95 \%$ of the preexercise capacity ${ }^{17}$.

Isometric peak torque for plantar flexors and dorsiflexors, with the ankle at neutral (0 degrees), was chosen for evaluating muscle strength because the ankle is usually at neutral in the standing position. This position was considered important because one of the objectives of this study was also evaluate the influence of training on balance. It is important to note that the muscle groups studied contribute towards standing positions or balance strategies that are responsible for avoiding falls ${ }^{10}$. Isometric evaluations were chosen in order to minimize errors during data collection. Errors could have arisen because some volunteers might have presented shorter ranges of motion because they were elderly and sedentary, and also had some difficulty in carrying out the isotonic evaluation for all ranges of motion to be established. Similarly, volunteers might also have presented some difficulty in understanding the requests to carry out isotonic ankle muscle contractions.

This training was supervised by physical therapists in order to ensure that the volunteers would strengthen the ankle muscles slowly and for all ranges of ankle motion, in accordance with the specificity of the training exercises. Therefore, some isometric muscle strength gains could be expected at neutral because all ranges of motion were included in the workload.
Increased production of strength probably occurs as a result of training the related neural adaptations. It has been reported that these neural adaptations are primary source of the gains in produced force observed over the first 8 weeks of training, whereas increases in muscle cross-sectional area (hypertrophy) are believed to be the primary source of the gains observed thereafter ${ }^{17}$.

In the present study, the plantar flexors were trained in accordance with the methods of Chandler et al. ${ }^{18}$ and Hauer et al. ${ }^{13}$, which confirm our research findings. Chandler et al. ${ }^{18}$ also trained dorsiflexors, although therabands were used.

Chandler et al. ${ }^{18}$ studied the effects of an exercise program for elderly volunteers that included resistance exercises for hip extension and abduction, knee flexion and extension, ankle dorsiflexion and lifted heel. After 10 weeks, the participants in the strength training program gained significantly greater strength than did the control subjects. The strength gained was significantly associated with improvement in mobility skills performance, gait velocity and fall efficacy. However, the initial level of frailty may affect the impact of strengthening on performance.

Hauer et al. ${ }^{13}$ studied the effects of exercise training on geriatric patients with a history of injurious falls. The control group carried out flexibility exercises, ball games, calisthenics and memory tasks while seated. The intervention group exercised on stationary bicycles, performed a regimen of highintensity progressive resistance training for knee extension, hip extension, hip abduction and ankle plantar flexion, and performed balance training in the static and dynamic positions. The exercise improved muscle strength significantly. The differences between the two groups were still significant three months after the training ended, because of the large initial gain in strength in the intervention group. There were no significant losses during the follow-up period. The patients in the control group did not improve their strength.

Hartard et al. ${ }^{19}$ studied the effects of resistance training for postmenopausal women with osteopenia. After six weeks, the training group showed no significant changes in the lumbar spine and femoral neck BMD, whereas the control group demonstrated significant loss of BMD, especially in the femoral neck. These results may justify the need for muscle strength to prevent decreased BMD. Despite the small influence of muscle strength and physical activity on BMD, increased physical activity may prevent fractures by preventing falls and limiting the deleterious effects of falling ${ }^{20}$.

Although Chandler et al. ${ }^{18}$ did not find a relationship between gain in strength and improvement in balance performance measurements, there was a significant relationship between strength gain and the fall efficacy scale, thus suggesting that a gain in strength has a positive influence on an individual's confidence in his or her ability to avoid falls. These authors suggested that the duration or intensity of their training program might have been insufficient to effect a more direct impact on balance performance measurements. 
The present study showed a significant decrease of $16 \%$ in the balance performance index, thereby indicating better balance performance. Other authors have also achieved some success in their training programs.

These results confirm the findings of Grahn Kronhed et al. ${ }^{11}$, who showed that there was significant single-leg stance improvement with closed eyes among adults with low $\mathrm{BMD}$, after a year of resistance and balance training, stretching exercises and relaxation.

On the other hand, Hauer et al. ${ }^{13}$ trained geriatric patients with a history of injurious falls and obtained an improvement in balance performance in the intervention group, which carried out high-intensity progressive resistance training and balance training in the static and dynamic positions. The effects from the training in the intervention group were partly lost during the follow-up period, but some performance levels still remained significantly higher than the baseline levels or performance levels of the control group, because of the large initial improvement during training.

Binder et al. ${ }^{21}$ trained elderly adults by means of flexibility exercises, balance and coordination training, progressive resistance training and endurance training at an intensity level that elicited approximately $65 \%$ to $70 \%$ of peak $\mathrm{VO}_{2}$. The control group carried out a home exercise program focused on flexibility exercises. The exercise training participants had significant improvements in maximum voluntary knee extensor and flexor torque and one-leg stance time and these changes were significantly greater than the changes in the control group. Performance levels using the Berg Balance Scale showed more improvement in the exercise group. This group also presented more improvement in physical function.

Judge et al. ${ }^{22}$ concluded that walking and postural training, and muscle control rather than muscle strength development may be the critical variables determining singleleg stance balance following moderate resistance training. Thus, leg strength is probably a necessary but insufficient condition for maintaining single-leg stance balance.

Navega et al. ${ }^{23}$ evaluated women with osteoporosis by means of the same balance protocol as used in the present study. After fourteen weeks of training, there was a significant balance performance index improvement. However, differing from the present study, their exercise training program included stretching, walking and thigh muscle strengthening.

Steadman et al. ${ }^{24}$ proposed two balance training protocols and, regardless of which strategy was utilized, a significant balance performance improvement was found, as evaluated by the Berg Balance Scale.

Every exercise proposed in the present study may have contributed towards significant balance performance index decreases. Ankle muscle resistance training, walking and balance training may not only have contributed towards significant balance performance improvement, but also strengthened other muscle groups. The training proposed was sufficient to achieve the purpose of the study, but comparison of different training exercises is still needed for evaluating which exercises are the most effective. Balance training may have contributed towards better postural control and ankle muscle strengthening, and consequently also towards greater independence for patients.

The effect of twelve weeks of resistance and balance training on strength and gait measurements among elderly people was tested in a randomized controlled trial by Judge et al. ${ }^{25}$. The exercise group presented significant improvement only in relation to usual gait velocity, but the control group did not present any changes in velocity after flexibility training. Because gait velocity declines at a rate of $12 \%$ to $16 \%$ per decade, Judge et al. ${ }^{25}$ concluded that the $8 \%$ improvement in velocity that they found was clinically significant.

The exercise training group in the present study presented significant improvement in usual and maximum gait velocities, by $4.8 \%$ and $4.6 \%$, respectively, thus differing from the findings of Judge et al. ${ }^{25}$. The latter study did not include plantar flexor training (which was utilized in our study), and this difference may have contributed towards the increase in gait velocity in our study.

Chandler et al. ${ }^{18}$ and Hauer et al. ${ }^{13}$ also obtained an improvement in usual gait velocity following exercise training programs. However, the exercise training proposed by Hauer et al. ${ }^{13}$ consisted not only of resistance training but also of balance training in static and dynamic positions, among geriatric patients with a history of injurious falls.

Steadman et al. ${ }^{24}$ only found significant improvement in gait velocity for the group that underwent conventional therapy plus additional activities consisting of the repetition of a series of specific graded tasks in order to achieve functional balance through meeting distance and time targets.

In the present study, not only the balance improvement, but also the increase in peak torque for the plantar flexors and dorsiflexors may have influenced gait velocity.

The similarity of the regression lines in the study by Judge et al. ${ }^{25}$ gives support for a hypothesis that improvement in strength will improve gait velocity, especially in subjects whose strength is below a leg weakness threshold. The greatest improvements occurred in subjects who walked slowly at baseline. However, people who had excellent muscle strength at baseline also increased their gait velocity. These authors' conservative interpretation was that gait velocity improved regardless of baseline velocity, and that it was not possible to determine whether increases in gait velocity were due to improvements in strength or to improvements in balance function.

Regardless of the positive results in the present study, the absence of a control group is a serious limitation. The control group was excluded from this study because of the restrictions of National Health Council Resolution 196/96. Therefore, it is not possible to state that these outcomes resulted from the exercise training program alone. It is possible, however, to affirm that exercise training programs among 
women with osteoporosis do have some effect through holding back the decline in strength and muscle mass over the course of old age and the accompanying loss of independent functional capacity that have previously been proven. To obtain approval from Research Ethics Committees for the use of control groups in future larger studies, there will need to be proposals for the implementation of exercise training programs for the volunteers who made up the control group that will carried out after positive final results have been found. Through this, the study conclusions will then be more reliable.

\section{CONCLUSIONS}

In summary, it can be concluded from the results obtained that the physical activity program may have had a role in improving the range of variables evaluated among this group of patients. The results suggest that exercise training programs are efficient in improving balance performance, gait velocity and ankle muscle strength. All of these outcomes can mediate a reduction in the risk of osteoporotic fractures through their influence on multiple risk factors.

Despite the small size of the sample studied and the absence of a control group, the exercises proposed in this study were shown to be efficient and easily performed. As well they only required inexpensive instruments. This is significant because the training sessions were directed towards people living on the limited income of average Brazilian salaries. Because of the low cost, participants can afford to continue the training without the supervision of a physical therapist after the 12-week training program, thus suggesting that this accessible method may have beneficial effects for this Brazilian population.

Acknowledgements: The authors wish to especially thank the volunteers whose keen interest and dedication made this study possible.

\section{REFERENCES}

1. Rocha FAC, Ribeiro AR. Low incidence of hip fractures in an equatorial area. Osteoporos Int. 2003; (14): 496-9.

2. Dennison E, Cooper C. Epidemiology of osteoporotic fractures. Horm Res. 2000; (54): 58-63.

3. Kanis JA, Pitt EA. Epidemiology of osteoporosis. Bone. 1992; (Suppl 3): S7-15.

4. Riggs BL, Melton III LJ. The worldwide problem of osteoporosis: insights afforded by epidemiology. Bone. 1995; 17 (Suppl 50): 5S-11.

5. Dargent-Molina P, Douchin MN, Cormier C, Meunier PJ, Bréart G. Use of clinical risk factors in elderly women with low bone mineral density to identify women at higher risk of hip fracture: the EPIDOS prospective study. Osteoporos Int. 2002; (13): 593-9.
6. Perracini MR, Ramos LR. Fall-related factors in a cohort of elderly community residents. Rev Saúde Pública. 2002; (36): 709-16.

7. Williams GN, Higgins MJ, Lewek MD. Aging skeletal muscle: physiologic changes and the effects of training. Phys Ther. 2002; (82): 62-8.

8. Danneskoild-Samsoe B, Kofod V, Munter J, Grimby G, Schnohr P. Muscle strength and functional capacity in 77-81 year old men and women. Eur J Appl Physiol. 1984; (52): 123-35.

9. Rutherford OM, Jones DA. The relationship of muscle and bone loss and activity levels with age in women. Age Ageing. 1992; (21): 286-93.

10. Daubney ME, Culham EG. Lower-extremity muscle force and balance performance in adults aged 65 years and older. Phys Ther. 1999; (79): 1177-85.

11. Grahn Kronhed AC, Moller M. Effects of physical exercise on bone mass, balance skill and aerobic capacity in women and men with low bone mineral density, after one year of training a prospective study. Scand J Med Sci Sports. 1998; (8): 290-8.

12. Kerschan K, Alacamlioglu Y, Kollmitzer J, Wöber C, Kaider A, Hartard M, et al. Functional impact of unvarying exercise program in women after menopause. Am J Phys Med Rehabil. 1998; (77): 326-32.

13. Hauer K, Rost B, Rütschle K, Opitz H, Specht N, Bartsch P, et al. Exercise training for rehabilitation and secondary prevention of falls in geriatric patients with a history of injurious falls. JAGS. 2001; (49):10-20.

14. Nelson ME, Fiatarone MA, Morganti CM, Trice I, Greenberg RA, Evans WJ. Effects of high-intensity strength training on multiple risk factors for osteoporotic fractures: a randomized controlled trial. JAMA. 1994; (272): 1909-14.

15. Caromano, RA Effects of training and maintenance of low-tomoderate intensity physical exercises in health, sedentary old people. [Thesis]. São Paulo: São Paulo University. Institute of Psychology. 1998.

16. Brown AB, McCartney N, Sale DG. Positive adaptations to weight-lifting training in the elderly. J Appl Physiol. 1990; (69): 1725-33.

17. Kraemer WJ, Fleck SJ, Evans WJ. Strength and power training: physiological mechanisms of adaptation. Exerc Sport Sci Ver. 1996; (24): 363-97.

18. Chandler JM, Duncan PW, Kochersberger G, Studenski S. Is lower extremity strength gain associated with improvement in physical performance and disability in frail, communitydwelling elders? Arch Phys Med Rehabil. 1998; (79): 24-30.

19. Hartard M, Haber P, Ilieva D, Preisinger E, Seidl G, Huber J. Systematic strength training as a model of therapeutic intervention: A controlled trial in postmenopausal women with osteopenia. Am J Phys Med Rehabil. 1996; (75): 21-8.

20. Gerdhem P, Ringsberg KAM, Akessom K, Obrant KJ. Influence of muscle strength, physical activity and weight on bone mass in a population-based sample of 1004 elderly women. Osteoporos Int. 2003; (14): 768-72.

21. Binder EF, Schechtman KB, Ehsani AA, Steger-May K, Brown $\mathrm{M}$, Sinacore DR, et al. Effects of exercise training on frailty in community-dwelling older adults: results of a randomized, controlled trial. JAGS. 2002; (50): 1921-8. 
22. Judge JO, Lindsey C, Underwood M, Winsemius D. Balance improvements in older women: effects of exercise training. Phys Ther. 1993; (73): 254-62.

23. Navega MT, Aveiro MC, Oishi J. Stretching, walking and strengthening of thigh muscles: a physical activity program to osteoporotic women. Rev Bras Fisiot. 2003; (7): 261-7.
24. Steadman J, Donaldson N, Kalra L. A randomized controlled trial of an enhanced balance training program to improve mobility and reduce falls in elderly patients. JAGS. 2003; (51): 847-52.

25. Judge JO, Underwood M, Gennosa T. Exercise to improve gait velocity in older persons. Arch Phys Med Rehabil. 1993; (74): 400-6. 